\title{
Solvothermal synthesis of high molecular weight dithienogermole containing conjugated polymers
}

\author{
FEI-BAO ZHANG*, SU-FANG LV, JIANG-XIONG JIANG and YONG NI* \\ Key Laboratory of Organosilicon Chemistry and Material Technology of Ministry of Education, Hangzhou \\ Normal University, Hangzhou 310012, China \\ e-mail: feibaozhang@126.com; 20020806@hznu.edu.cn
}

MS received 5 September 2014; revised 27 December 2014; accepted 6 February 2015

\begin{abstract}
Dithienogermole-diphthalimide, a new molecule, and dithienogermole-dithiadiazole alternate polymers were synthesized by the solvothermal method. Optical properties and molecular weight were investigated by UV-Vis absorption spectroscopy and Gel Permeation Chromatography. Compared with the results achieved by the previously reported normal heating method, these polymers reported here exhibited similar optical properties and possess higher molecular weight.
\end{abstract}

Keywords. Donor-acceptor polymers; solvothermal synthesis; optical; polycondensation

\section{Introduction}

The Stille coupling reactions, known as palladium catalyzed cross-coupling of organostannanes with organichalides, are an important and versatile method to form carbon-carbon bonds. ${ }^{1-4}$ This coupling method has been widely used to synthesize numerous organic compounds, especially to synthesize conjugated polyaromatic polymers, which are important materials in polymer solar cells (PSCs), organic light-emitting diodes (OLED), and organic field effect transistors (OFET). Recently, many efforts have been focused on developing effective heating procedures to improve the molecular weight and lower polydispersity of the products. ${ }^{5-8}$ However, most of these reactions were implemented in the traditional Stille heating method with several limitations. Its reaction time would last 35 days or even longer, the reactants are sensitive and easy to be polluted by air. To push the method forward, several groups have tried microwave irradiation method and achieved remarkable improvement of molecular weight and polydispersity but the microwave equipment needed is very expensive. ${ }^{9-12}$ Therefore, development of a simple method to synthesize donor-acceptor type alternate polymers with mild condition and at low cost is still the most important goal for most material scientists.

In this paper, we report a novel strategy to synthesize dithienogermole (DTG) containing polymers via a solvothermal method. The solvothermal method

\footnotetext{
*For correspondence
}

has been used as an effective method to prepare inorganic materials, such as $\mathrm{TiO}_{2}, \mathrm{CdS}$, and $\mathrm{MnO}_{2} \cdot{ }^{13-15}$ In the solvothermal process, the reactions would be purely heterogeneous at temperatures above the boiling point of the organic solvents in a closed system at $1 \mathrm{~atm}$ pressure or more. The solvothermal method has many advantages, such as fast reaction kinetics, short processing times, high yield, composite formation, cost-effective, environmentally benign, and easily scalable. To our knowledge, there are few reports about synthesizing DTG containing polymers based on the solvothermal method. ${ }^{16-20}$ In the solvothermal process, the Stille polycondensation would be purely heterogeneous at high temperatures above the boiling point of organic solvents in a closed system at $1 \mathrm{~atm}$ pressure or more. It would lead to a rapid and reproducible synthesis of copolymers with high molecular weight and high yields. This method may be a new way to synthesize donor-acceptor type alternate polymers.

\section{Experimental}

\subsection{Materials and methods}

All reagents used in this work were mainly purchased from Aldrich, Alfa Aesar and Aladdin Industrial Corporation. Tetrahydrofuran (THF) and ether were purified by refluxing with sodium/benzophenone. Anhydrous chlorobenzene was distilled from calcium hydride. All reactions were performed under dry argon. These solvents were stored over activated molecular sieves until use. Monomers, bis(2-ethylhexyl)bis 
(trimethylstannyl)dithienogermole $\left(\mathrm{DTGSn}_{2}\right),{ }^{21} \mathrm{~N}$-(2ethylhexyl)-3,6-dibromophthalimide(PH), ${ }^{22}$ 4,7-Dibromobenzo[c] $]^{1,2,5}$ thiadiazole $(\mathrm{BTA})^{21}$ were prepared according to the methods reported in the literature.

\section{1a Characterization: ${ }^{1} \mathrm{H}$ NMR and ${ }^{13} \mathrm{C}$ NMR spe-} ctra were obtained on Bruker AVANCE 400 instrument and referenced to the residual solvent peak $\mathrm{CDCl}_{3}$ : ${ }^{1} \mathrm{H}: \delta=7.26 \mathrm{ppm}, 13 \mathrm{C}: \delta=77.23 \mathrm{ppm}$. Gel permeation chromatography (GPC) was carried out with WaterBreeze GPC apparatus with THF as the eluent. Cyclic voltammetry (CV) was performed using Zahner IM6E. A solution of sample (1-2 mg) and tetrabutylammonium perchlorate (TBAP) was cast on a glass carbon disc electrode ( $3 \mathrm{~mm}$ diameter) and dried in vacuum $(<0.1$ Torr $)$ prior to the measurement, as the working electrode. Measurements of the samples were performed with a Pt plate as the counter electrode and an $\mathrm{Ag} / \mathrm{Ag}^{+}$reference electrode, in acetonitrile containing $0.1 \mathrm{M}$ TBAP, at a scan rate of $10 \mathrm{mV} / \mathrm{s}$.

Absorption spectra were measured with CARY 100 Conc UV-Vis spectrophotometer. Thermogravimetric analyses were performed under nitrogen flow using a TA Q50 instrument at a heating rate of $10^{\circ} \mathrm{C} \mathrm{min}^{-1}$.

\subsection{Synthesis of the polymers}

$\mathrm{N}$-(2-ethylhexyl)-3,6-dibromophthalimide (0.083 g, 0.2 mmol), bis(2- ethylhexyl)bis(trimethylstannyl)dithienogermole (DTGSn $, 0.158 \mathrm{~g}, 0.2 \mathrm{mmol}$ ), tris(dibenzylideneacetone)dipalladium(0) (3.6 mg, $2 \mathrm{~mol} \%)$, tri(otolyl)phosphine (6 mg, $10 \mathrm{~mol} \%)$, and chlorobenzene $(8 \mathrm{~mL})$ were put into a teflon-lined autoclave of 10 $\mathrm{mL}$ capacity. The autoclave was purged with a gentle stream of argon for $10 \mathrm{~min}$ and maintained at $160^{\circ} \mathrm{C}$ for $12 \mathrm{~h}$, and then cooled to room temperature naturally. To this was added $100 \mathrm{~mL}$ of methanol to precipitate polymeric substances. The polymeric substances were washed with hot methanol, hot acetone and then with hot hexane in a Soxhlet apparatus. Finally the methanol, acetone and hexane insoluble substances were extracted with hot chloroform. Evaporation of the solvent from the extract, followed by drying the residue under vacuum for 2 days at room temperature gave pDTG-PH as a deep red solid (106 mg, 74\% yield, $\mathrm{M}_{\mathrm{n}}=36.9 \mathrm{~K}, \mathrm{M}_{\mathrm{w}}=$ 51.4K PDI=1.39): ${ }^{1} \mathrm{H} \mathrm{NMR}\left(\mathrm{ppm}, \mathrm{CDCl}_{3}\right) 7.92$ (br, 2H), 7.82 (br, 2H), 3.62 (br, 2H), 1.90 (br, 1H), 1.45$1.15(\mathrm{~m}, 26 \mathrm{H}), 0.95-0.81$ (m, 18H). Polymer pDTGBTA was prepared in a manner similar to that above. Data for pDTG-BTA: black solids. $74 \mathrm{mg}, 78 \%$ yield. $\left.\mathrm{M}_{\mathrm{n}}=35.4 \mathrm{~K}, \mathrm{M}_{\mathrm{w}}=40.2 \mathrm{~K}, \mathrm{PDI}=1.13\right) .{ }^{1} \mathrm{H} \mathrm{NMR}$ (ppm, $\mathrm{CDCl}_{3}$ ) 8.21(br, 2H), 7.85(br, 2H), 2.12(br, 2H), $1.25-1.05(\mathrm{~m}, 20 \mathrm{H}), 0.89-0.75(\mathrm{~m}, 12 \mathrm{H})$.

\section{Results and Discussion}

\subsection{Synthesis and characterization}

Normally, there are two important methods to synthesize donor-acceptor (D-A) type conjugated polymers. The most popular one is conventional heating method and many D-A type polymers bearing DTG or dithienosiloles (DTS) ${ }^{1}$ were prepared by this method. Another one is microwave irradiation method, which was reported to get high molecular weight polymers and reduce reaction time. The solvothermal method described here also enables rapid and repeatable Stille polycondensation. For example, the polycondensation of bis(trimethylstannyl)dithienometallole $\left(\mathrm{DTGSn}_{2}\right)$ and aryl halides (PH and BTA) using $\mathrm{Pd}_{2}(\mathrm{dba})_{3} /(\mathrm{o}-\mathrm{Tol})_{3} \mathrm{P}$ as the catalyst, followed by purification of the resulting organic products by the Soxhlet extraction gave the target polymers with high molecular weight and low polydispersity index (PDI). The higher molecular weight of pDTG-PH may be ascribed to high solubility of the polymers than those of pDTG-BTA. The long branched alkyl chain in acceptor part may play an important role about the solubility of the polymer. Polymeric substances with high molecular weights were probably removed as solid materials which were insoluble in hot chloroform.

\subsection{UV-Vis absorption analysis of polymers}

UV-Vis absorption spectra of pDTG-PH and pDTGBTA were measured in chloroform and as solid thin film as shown in figure 1 . The absorptionmaxima $\left(\lambda_{\max }\right)$ for pDTG-PH in solution at room temperature occured at $501 \mathrm{~nm}$, which appeared at a lower energy than that of pDTS-PH (ca. $475 \mathrm{~nm}$ ) as reported in the literature. ${ }^{23} \mathrm{In}$ film, the absorption band also shifted to a longer wavelength $\left(\lambda_{\max } 511 \mathrm{~nm}\right)$ than that of pDTS-PH (ca. 494 $\mathrm{nm}$ ). The redshift in absorption maxima of pDTG-PH indicated the strong interchain interaction of DTG-PH. As reported previously, the UV-Vis spectra of pDTGBTA always showed similar broad absorption maxima at $656 \mathrm{~nm}$ and $697 \mathrm{~nm}$ in chloroform and as film, respectively, and the absorption maxima were longer than that of the present pDTG-BTA. ${ }^{21}$

\subsection{Electrochemical properties}

The CV measurements were carried out for the DTGpolymer films on glass carbon electrode at the rate of $10 \mathrm{mV} / \mathrm{s}$ (figure 2). The HOMO energy levels of pDTG$\mathrm{PH}$ and pDTG-BTA were calculated to be $-5.19 \mathrm{eV}$ and $5.1 \mathrm{eV}$, based on the $\mathrm{CV}$ oxidation onsets $\left(\mathrm{E}_{\mathrm{HOMO}} / \mathrm{eV}=\right.$ 


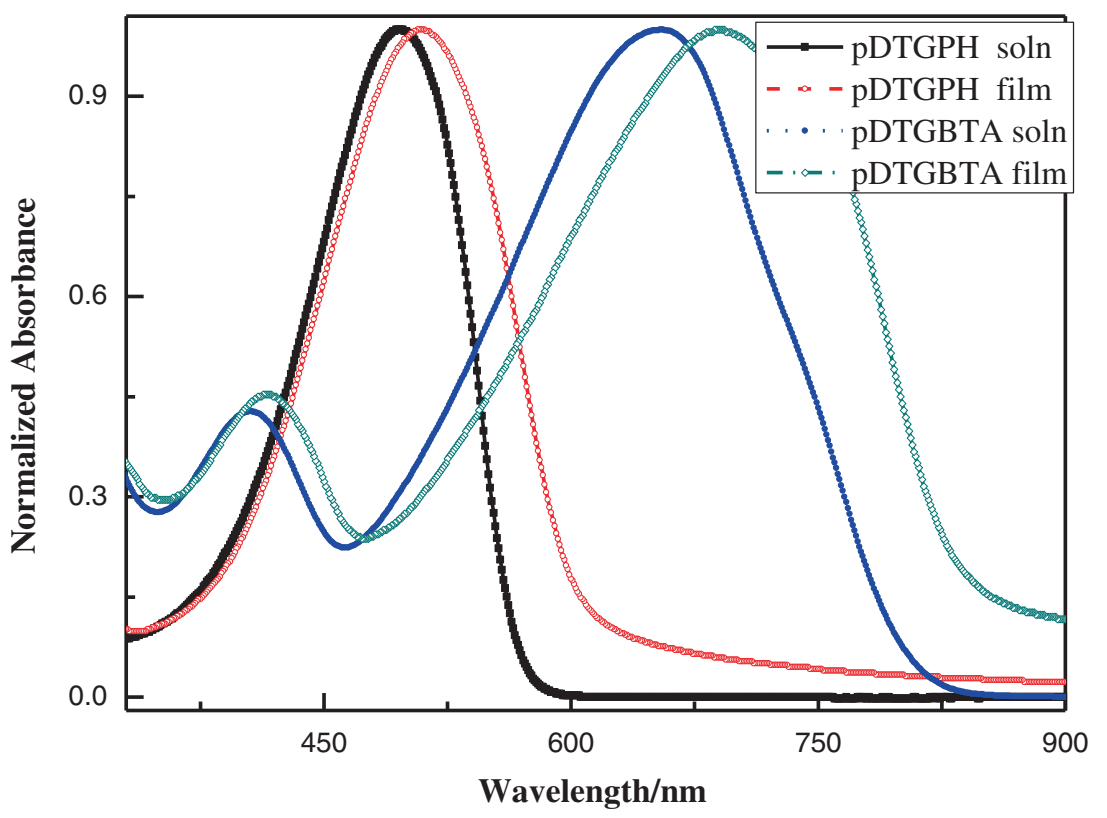

Figure 1. UV-Vis absorption spectra of DTG-containing polymers in chloroform.

-4.8-[ $\mathrm{E}_{\text {onset }}-\mathrm{E}_{1 / 2}$ (Ferrocene) $\left.] / \mathrm{V}\right)$, and the LUMO energy levels were calculated to be $-3.16 \mathrm{eV}$ (pDTG$\mathrm{PH}$ ) and $-3.62 \mathrm{eV}$ (pDTG-BTA) from the optical band gaps and the electrochemical HOMO energy levels. The onset oxidation potentials of the films were very similar to those reported for $\mathrm{pDTS}-\mathrm{PH}^{23}$ and pDTG-BTA. ${ }^{21,24}$

\subsection{Thermal stability of polymers}

Thermal stability of the polymers was investigated by thermogravimetric analysis (TGA) in nitrogen and 5\% weight loss temperatures $\left(T_{\mathrm{d}}^{5}\right)$ were noted as listed in table 1 . TGA of pDTG-PH revealed $T_{\mathrm{d}}^{5}=409^{\circ} \mathrm{C}$ and that of pDTG-BTA $398^{\circ} \mathrm{C}$. The two polymers

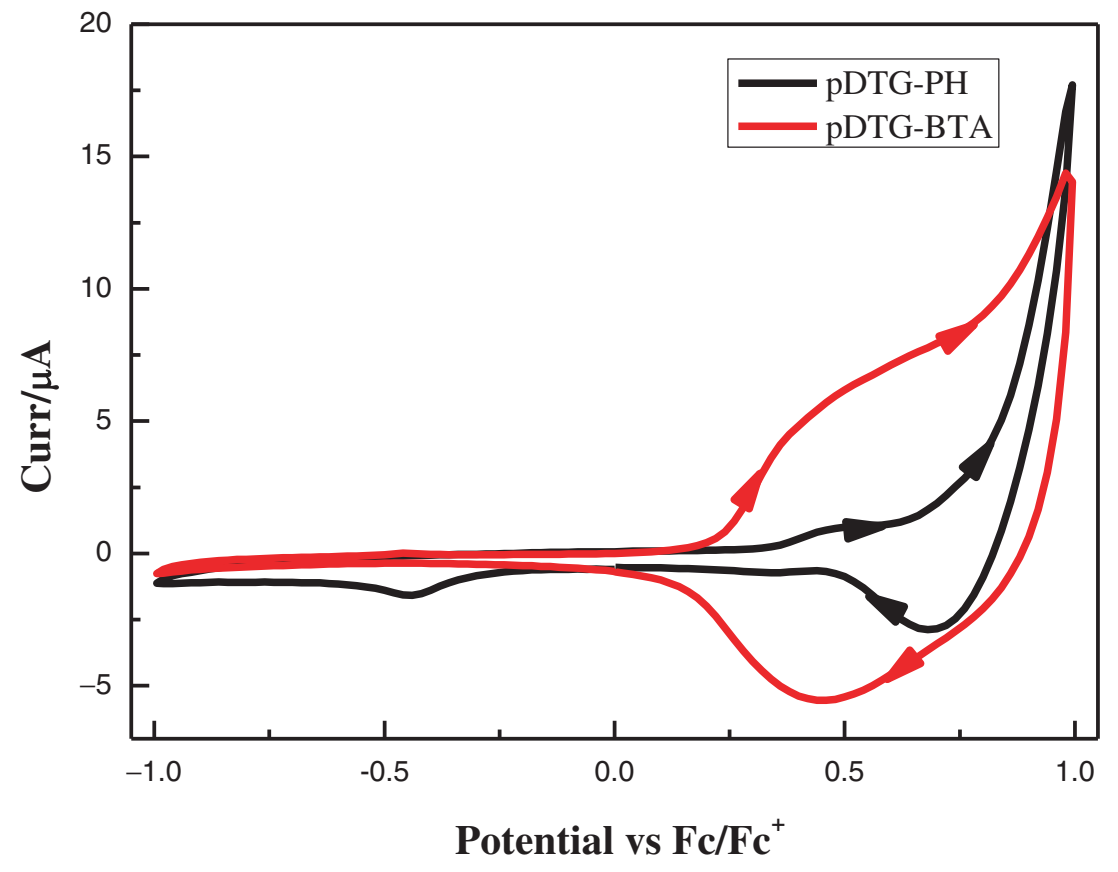

Figure 2. CVs of solid films of DTG-containing polymers. 
Table 1. Synthesis and properties of DTG-based polymers.

\begin{tabular}{lcccccccc}
\hline & & \multicolumn{7}{c}{$\lambda_{\max }^{\mathrm{ab}} / \mathrm{nm}$} \\
Polymer & Yield/\% $^{\mathrm{a}}$ & $\mathrm{M}_{\mathrm{n}}^{\mathrm{b}}$ & PDI & $\mathrm{CHCl}_{3}$ & film & $\mathrm{TGA}^{\mathrm{c}}\left(T_{d}^{5} /{ }^{\circ} \mathrm{C}\right)$ & $\mathrm{HOMO} \mathrm{eV}$ & LUMO eV \\
\hline DTG-PH $^{\mathrm{d}}$ & 74 & $36.9 \mathrm{~K}$ & 1.39 & 498 & 511 & 409 & -5.19 & -3.31 \\
DTG-BTA $^{\mathrm{d}}$ & 62 & $35.4 \mathrm{~K}$ & 1.13 & 656 & 693 & 398 & -5.1 & -3.35 \\
DTS-PH $^{\mathrm{e}}$ & 60 & $7.5 \mathrm{~K}$ & 2.24 & 475 & 494 & 240 & -5.25 & -3.0 \\
DTG-BTA $^{\mathrm{f}}$ & 40 & $0.8 \mathrm{~K}$ & 1.38 & 650 & 683 & - & - & - \\
DTS-BTA $^{\mathrm{g}}$ & 40 & $18 \mathrm{~K}$ & 1.2 & - & - & 250 & -5.05 & -3.27 \\
\hline
\end{tabular}

${ }^{a}$ After reprecipitation. ${ }^{b}$ Determined by GPC, relative to polystyrene standards. ${ }^{\mathrm{c}} 5 \%$ weight loss temperature. ${ }^{\mathrm{d}}$ Solvothermal method. ${ }^{\mathrm{e}, \mathrm{f}, \mathrm{g}}$ Literature data (reference $23,21,24$ ).

exhibited good thermal stability with $T_{\mathrm{d}}^{5}$ about $400^{\circ} \mathrm{C}$, which may be attributed to their high molecular weights.

\section{Conclusions}

In summary, pDTG-PH and pDTG-BTA polymers were successfully synthesized via a solvothermal method. The polymers had high molecular weight and narrow polydispersity index which resulted in a slightly longer wavelength absorption, and higher HOMO level than the reported polymers containing the $\mathrm{PH}$ and $\mathrm{BTA}^{21-24}$ analogues. In view of the low cost and environmentally benign nature of the material, this method is believed to have a great potential for large scale applications.

\section{Supplementary Information}

${ }^{1} \mathrm{H}$ spectra are submitted as supplementary information available at www.ias.ac.in/chemsci.

\section{Acknowledgements}

This research was supported by Zhejiang Provincial Natural Science Foundation of China under Grant No. Y4100131 and the Scientific Research Fund of Dunhuang Academy under Grant No.200808. We appreciate Prof. Joji Ohshita (Hiroshima University) for the kind help during this work.

\section{References}

1. Carsten B, He F, Son H J, Xu T and Yu L P 2011 Chem. Rev. 1111493

2. Lundin P M, Giri G and Bao Z N 2013 J. Polym. Sci., Part A: Polym. Chem. 51908

3. Serap G, Helmut N and Niyazi S S 2007 Chem. Rev. 107 1324

4. Gallagher W P, Terstiege I and Maleczka R E 2001 J. Am. Chem. Soc. 1233194

5. Stille J K 1986 Angew. Chem. Int. Ed. Engl. 25508
6. Mitchell T N 1992 Synthesis 9803

7. Hwang Y M, Ohshita J, Harima Y, Mizumo T, Ooyama Y, Morihara Y, Izawa T, Sugioka T and Fujita A 2011 Polymer $\mathbf{5 2} 3912$

8. Bao Z, Chan W K and Yu L 1995 J. Am. Chem. Soc. 117 12426

9. Coffin R C, Peet J, Rogers J and Bazan G C 2009 Nat. Chem. 1657

10. Chen J, Shu J, Schobloch S, Kroeger A, Graf R, Munoz-Espi R, Landfester K and Ziener U 2012 Macromolecules $\mathbf{4 5} 5108$

11. Al-Hashimi M, Labram J G, Watkins S, Motevalli M, Anthopoulos T D and Heeney M 2010 Org. Lett. 12 5478

12. Bunnagel T W, Nehls B S, Galbrecht F, Schottler K, Kudla C J, Volk M and Pina J 2008 de Melo J S S, Burrows H D and Scherf U J. Polym. Sci., Part A: Polym. Chem. 467342

13. Zhang F B and Li H L 2007 Mater. Sci. Eng. C. 2780

14. Chen Y T, Zhang W, Zhang F B, Zhang Z X, Zhou B Z and Li H L 2004 Mater. Lett. 582761

15. Ko W Y, Chen L J, Chen Y H, Chen W H, Lu K M, Yang J R, Yen Y C and Lin K J 2013 J. Phys. Chem. C 11716290

16. Amb C M, Chen S, Graham K R, Subbiah J, Small C E, So F and Reynolds J R 2011 J. Am. Chem. Soc. 13310062

17. Small C E, Chen S, Subbiah J, Amb C M, Tsang S W, Lai T H, Reynolds J R and So F 2012 Nat. Photon. 6115

18. Zhang F B, Ohshita J, Miyazaki M, Tanaka D and Morihara Y 2014 Polymer J. 351

19. Zhong H L, Li Z, Buchaca-Domingo E, Rossbauer S, Watkins S E, Stingelin N, Anthopoulos T D and Heeney M 2013 J. Mater. Chem. A 4714973

20. Yau C P, Fei Z, Ashraf R S, Ashraf R S, Shahid M, Watkins S, Pattanasattayavong P, Anthopoulos T D, Gregoriou V G, Chochos C L and Heeney M 2014 Adv. Funct. Mater. 24678

21. Ohshita J, Hwang Y M, Mizumo T, Yoshida H, Ooyama Y, Harima Y and Kunugi Y 2011 Organometallics 30 3233

22. Guo X, Kim F S, Jenekhe S A and Watson M D 2009 J. Am. Chem. Soc. 1317206

23. Zhang M J, Guo X, Zhang Z G and Li Y F 2011 Polymer 525464

24. Hou J, Chen H Y, Zhang S, Li G and Yang Y 2008 J. Am. Chem. Soc. 13016144 